\title{
The effect of a centralization procedure for extruded lateral meniscus on load distribution in porcine knee joints at different flexion angles
}

Rei Kubota ${ }^{1}$, Hideyuki Koga ${ }^{2}$, Nobutake Ozeki ${ }^{1 *}$, Junpei Matsuda', Yuji Kohno ${ }^{1}$, Mitsuru Mizuno ${ }^{1}$, Hisako Katano ${ }^{1}$ and Ichiro Sekiya ${ }^{1}$

\begin{abstract}
Background: Meniscal extrusion results in loss of the ability to resist hoop strain and biomechanical overload on the joint articular surface. A centralization technique has been developed to overcome these problems. In this study, we analyzed the biomechanics of the extruded and centralized lateral meniscus (LM) in porcine knee joints at different flexion angles.
\end{abstract}

Methods: Porcine knee joints $(n=8)$ were set in the universal tester and each knee was tested under the following states: 1) intact; 2) extrusion - meniscal extrusion was created by resecting the posterior root of the LM and posterior synovial capsule; and 3) centralization - centralization was performed by two anchors inserted in the lateral tibial plateau. Deviation distance of the meniscus, contact pressure, and contact area in the anterior LM, middle $L M$, posterior $L M$, and the contact pressure of the tibial cartilage were evaluated with an axial compressive force of $200 \mathrm{~N}$ at knee flexion angles of $30^{\circ}, 45^{\circ}, 60^{\circ}$, and $90^{\circ}$.

Results: The deviation distance of LM significantly increased in extrusion but was restored to the intact status after centralization at all angles. Both the contact pressure and area significantly decreased in extrusion and were restored after centralization close to the intact status in the anterior and middle LM; in the posterior LM, however, decreased contact pressure and area were not restored after centralization. The contact pressure of the tibial cartilage increased significantly in extrusion but decreased close to the intact status after centralization.

Conclusions: This centralization procedure could reduce extrusion of the LM and restore the load-distributing function of the anterior-middle LM. However, the procedure itself could not restore hoop function in cases where the defect lies in the posterior LM.

Keywords: Meniscus, Meniscal extrusion, Centralization, Load distribution analyses

\footnotetext{
* Correspondence: ozeki.arm@tmd.ac.jp

${ }^{1}$ Center for Stem Cell and Regenerative Medicine, Tokyo Medical and Dental

University, 1-5-45 Yushima, Bunkyo-ku, Tokyo 113-8510, Japan

Full list of author information is available at the end of the article
}

(c) The Author(s). 2020 Open Access This article is licensed under a Creative Commons Attribution 4.0 International License, which permits use, sharing, adaptation, distribution and reproduction in any medium or format, as long as you give appropriate credit to the original author(s) and the source, provide a link to the Creative Commons licence, and indicate if changes were made. The images or other third party material in this article are included in the article's Creative Commons licence, unless indicated otherwise in a credit line to the material. If material is not included in the article's Creative Commons licence and your intended use is not permitted by statutory regulation or exceeds the permitted use, you will need to obtain permission directly from the copyright holder. To view a copy of this licence, visit http://creativecommons.org/licenses/by/4.0/ The Creative Commons Public Domain Dedication waiver (http://creativecommons.org/publicdomain/zero/1.0/) applies to the data made available in this article, unless otherwise stated in a credit line to the data. 


\section{Background}

Meniscal extrusion induces dysfunction of load distribution, one of the most important functions of the meniscus [1-3]. It is caused by the disruption of the meniscus hoop function and is often observed after meniscectomy [1, 4], meniscus root tears [5], and with aging [6-8]. Meniscal extrusion initiates osteoarthritis (OA) and accompanies its progression [9-11]. Restoring the lost function caused by meniscus extrusion can delay OA progression [12].

A centralization technique has been developed to reduce meniscal extrusion; the capsule attached to the meniscus is sutured to the edge of the tibial plateau using suture anchors [13]. Arthroscopic centralization of the extruded lateral meniscus (LM) improved clinical outcomes at twoyear follow-up [14]. It also increased the radiographic lateral joint space width on standing at the $45^{\circ}$ flexion view at 3 months; this was maintained for 2 years [14].

Biomechanical studies examining the effects of centralization are still limited, although some papers were recently published [15-17]. We already reported the biomechanical analysis of the centralization procedure for extruded LM with posterior root deficiency in a porcine model. Although this study showed that the centralization procedure restored the load distribution to a value closer to that of the normal knee joint, the experiment was performed only at $45^{\circ}$ of knee flexion [15] and

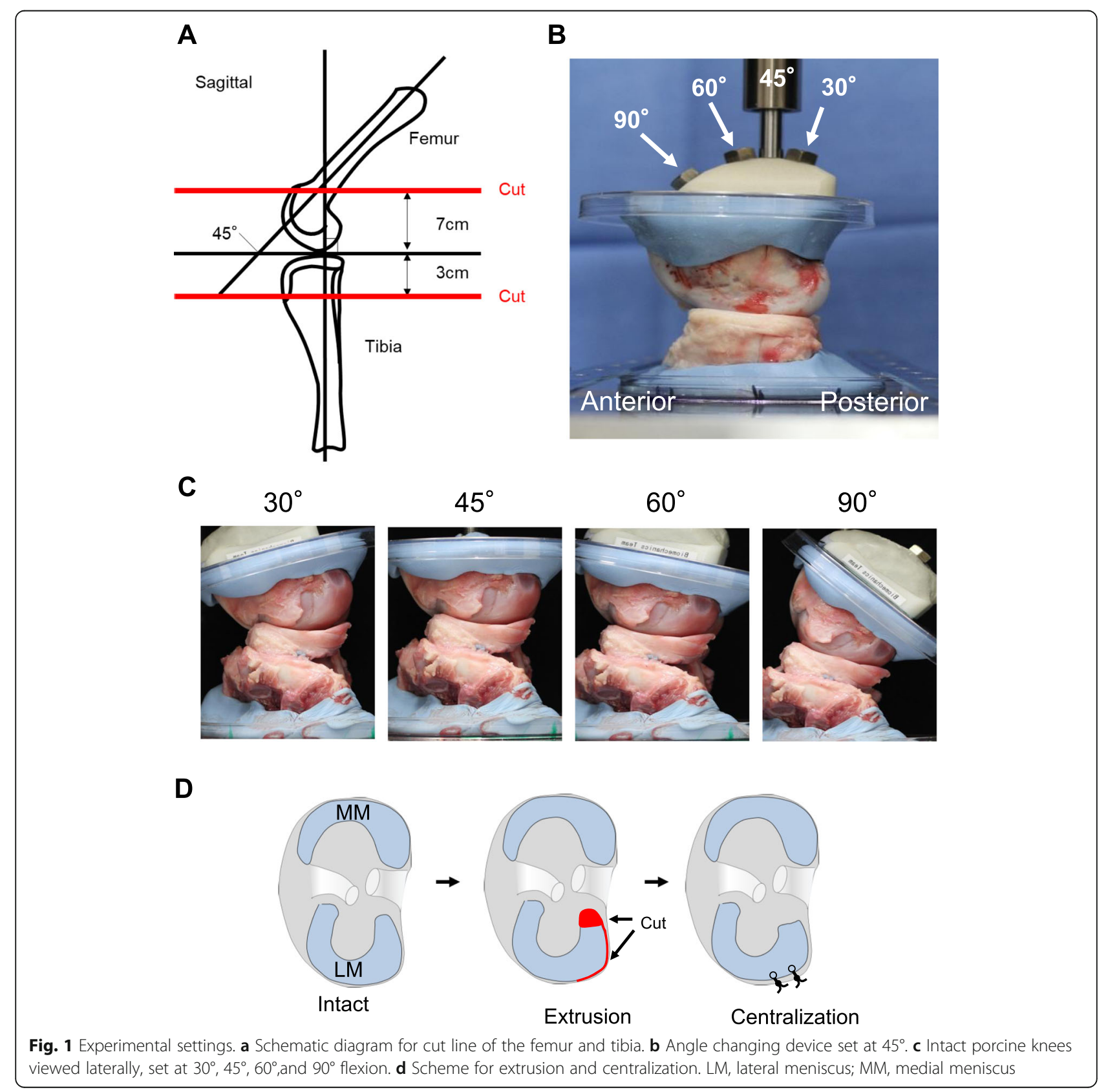


the effects of centralization in the more extended and more flexed knee position remained unknown. The purpose of the current study was, therefore, to analyze the effects of the centralization procedure in porcine knee joints at different flexion angles (as well as at $45^{\circ}$ ) in order to further clarify the biomechanical properties of the centralization procedure.

\section{Methods}

\section{Porcine knee joints}

We used porcine knee joints (Tokyo Shibaura Zouki, Tokyo, Japan), which were fresh-frozen and only right-side.
We excluded knees with damaged meniscus or cartilage. We analyzed only the lateral compartment in eight right knees.

\section{Experimental setup}

After the muscles were removed, we cut the tibia bone horizontally at $3 \mathrm{~cm}$ distal to the joint and the femoral bone obliquely at $45^{\circ}$ at $7 \mathrm{~cm}$ proximal from the joint. Then, we fixed the femur bone and tibia bone with a tester using polymethyl methacrylate (Fig. 1a). We cut the lateral collateral ligament (LCL) and inserted the sensor seat. We preserved the medial collateral ligament,

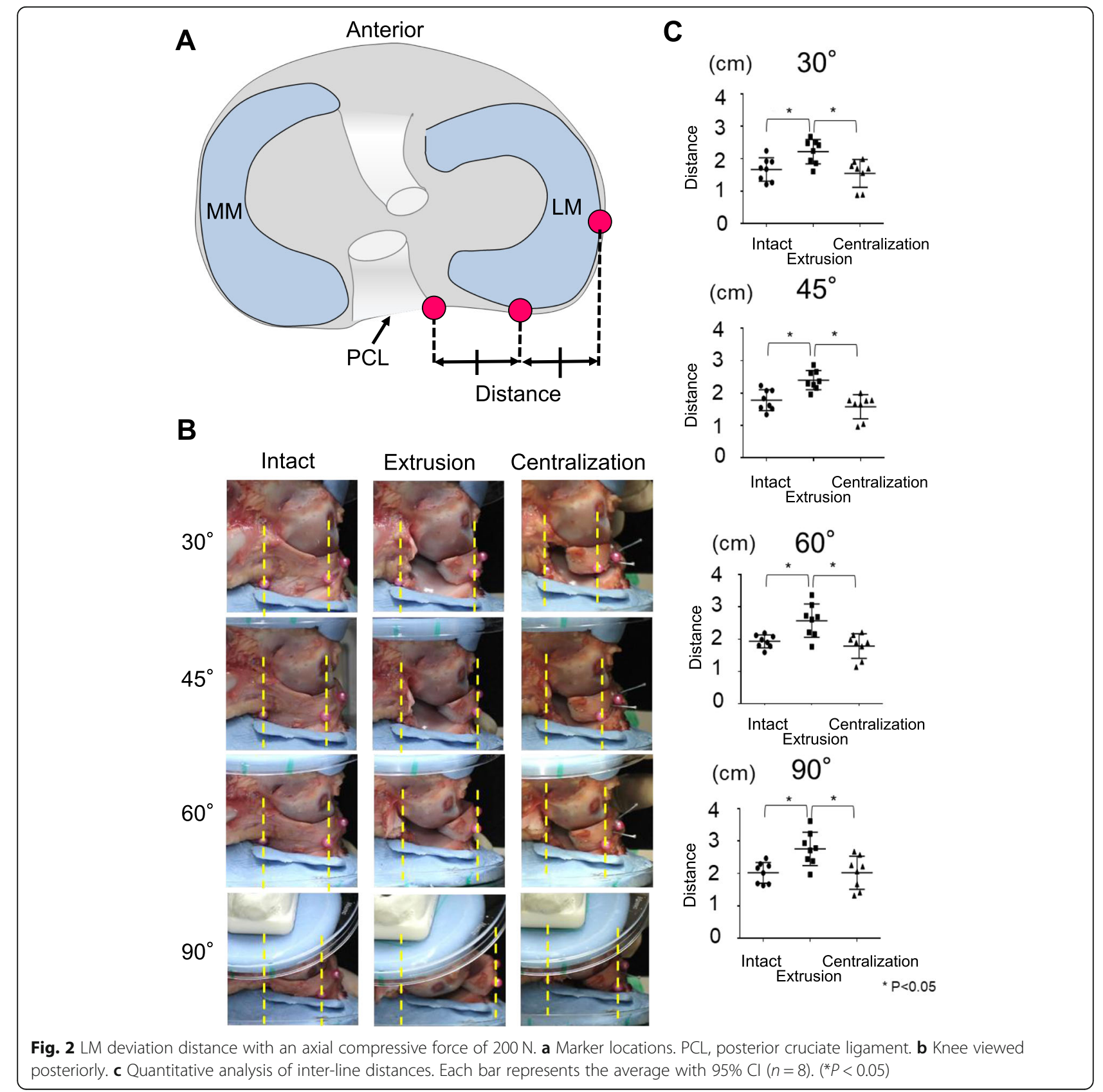


anterior cruciate ligament (ACL), and posterior cruciate ligament (PCL). The angle-changing device was placed between the knee and a universal testing machine (Fig. 1b), so that the knee flexion angles could be set at $30^{\circ}, 45^{\circ}, 60^{\circ}$, and $90^{\circ}$ (Fig. 1c).

The mechanical setup was as follows: 1) Intact; 2) Extrusion-we removed a $1 \mathrm{~cm}$ width of the posterior root of the LM to preclude anatomical repair, cut the posterior capsule horizontally from the posterior root attachment site of the posterior root, and created meniscal extrusion (Fig. 1d); and 3) Centralization-we inserted the first $1.4 \mathrm{~mm}$ soft anchor (JuggerKnot, Zimmer Biomet, Warsaw, IN, USA) into the lateral tibial plateau 1 $\mathrm{cm}$ anterior to the popliteal hiatus, the second $1.4 \mathrm{~mm}$ soft anchor into the lateral tibial plateau $1 \mathrm{~cm}$ anterior to the first anchor, and reduced the extruded meniscus to its original position (Fig. 1d). We passed the sutures through the border between the meniscus and the remaining capsule attached to the meniscus and secured to the tibia using mattress sutures. For all angles, an axial compressive force of $200 \mathrm{~N}$ was applied in each setting $[15,18]$.

\section{Deviation distance of the lateral meniscus}

Three spherical red plastic markers ( $3 \mathrm{~mm}$ diameter) were attached: the posterior marker at the center of the tibial attachment of the PCL; the lateral marker at the lateral

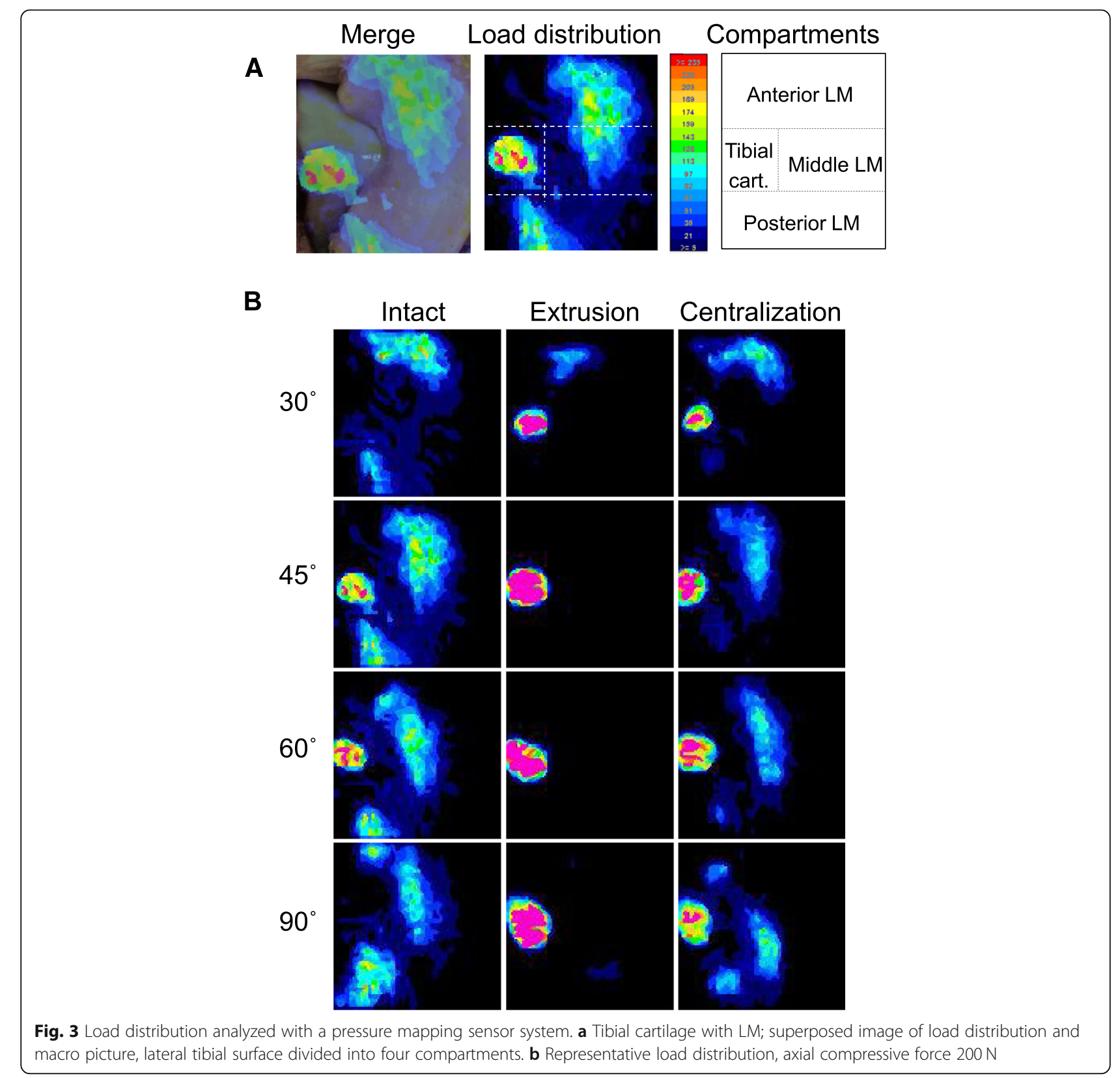


edge of the LM in the posterior view; and the posterolateral marker at the point where the middle line of the other two points intersects the outer edge of the meniscus in the posterior view (Fig. 2a). We placed the markers anterior to the resection. After application of an axial compressive force of $200 \mathrm{~N}$, the LM was photographed in the posterior view and the distance between the posterior marker line and the posterolateral marker line measured to evaluate the meniscal extrusion (Fig. 2a).

\section{Contact area and force measurements}

We used a pressure mapping sensor (Tekscan, Inc. South Boston, MA, USA) to quantify the distribution of load-bearing force on the lateral compartment. Tekscan enabled electronic scanning to measure the real-time force and contact area. We placed the sensor on the femoral side of the lateral meniscus and recorded the load distribution, as well as contact area, maximum contact pressure, and average contact pressure. We analyzed the data with MATLAB ${ }^{\circ}$ (MathWorks, MA, USA).

\section{Statistics}

We used the Friedman one-way non-parametric test and Dunn's test as post hoc tests using Prism 6 software (GraphPad Inc., La Jolla, CA, USA). $P$ values of less than 0.05 were considered statistically significant. All data were shown as means with $95 \%$ confidence intervals $(\mathrm{CI})$.

\section{Results}

The distance between the two markers significantly increased after extrusion at all flexion angles (Fig. 2b, c; Supplementary Table 1). Conversely, it significantly decreased after centralization at each flexion angle. In all settings, the distance between the two markers increased with the knee flexion angle, although there were no significant differences among the distances measured for each angle (Supplementary Table 1).

For load distribution analyses, the lateral compartment was divided into the anterior LM, the middle LM, the posterior LM, and the tibial cartilage areas (Fig. 3a). For each angle, according to the representative images (Fig. 3b), the load was concentrated on the tibial cartilage after extrusion and redistributed to the anterior and middle LM after centralization.

The average contact pressure in the anterior and middle LM decreased significantly after extrusion and increased after centralization. Similar results were obtained for each flexion angle, except in the anterior LM at $30^{\circ}$ and the middle LM at both $30^{\circ}$ and $90^{\circ}$ (Fig. 4, Supplementary Table 2). On the other hand, while extrusion significantly decreased the average contact pressure in the posterior LM, centralization did not fully restore it. Similar results were obtained for each flexion angle. In the anterior LM,

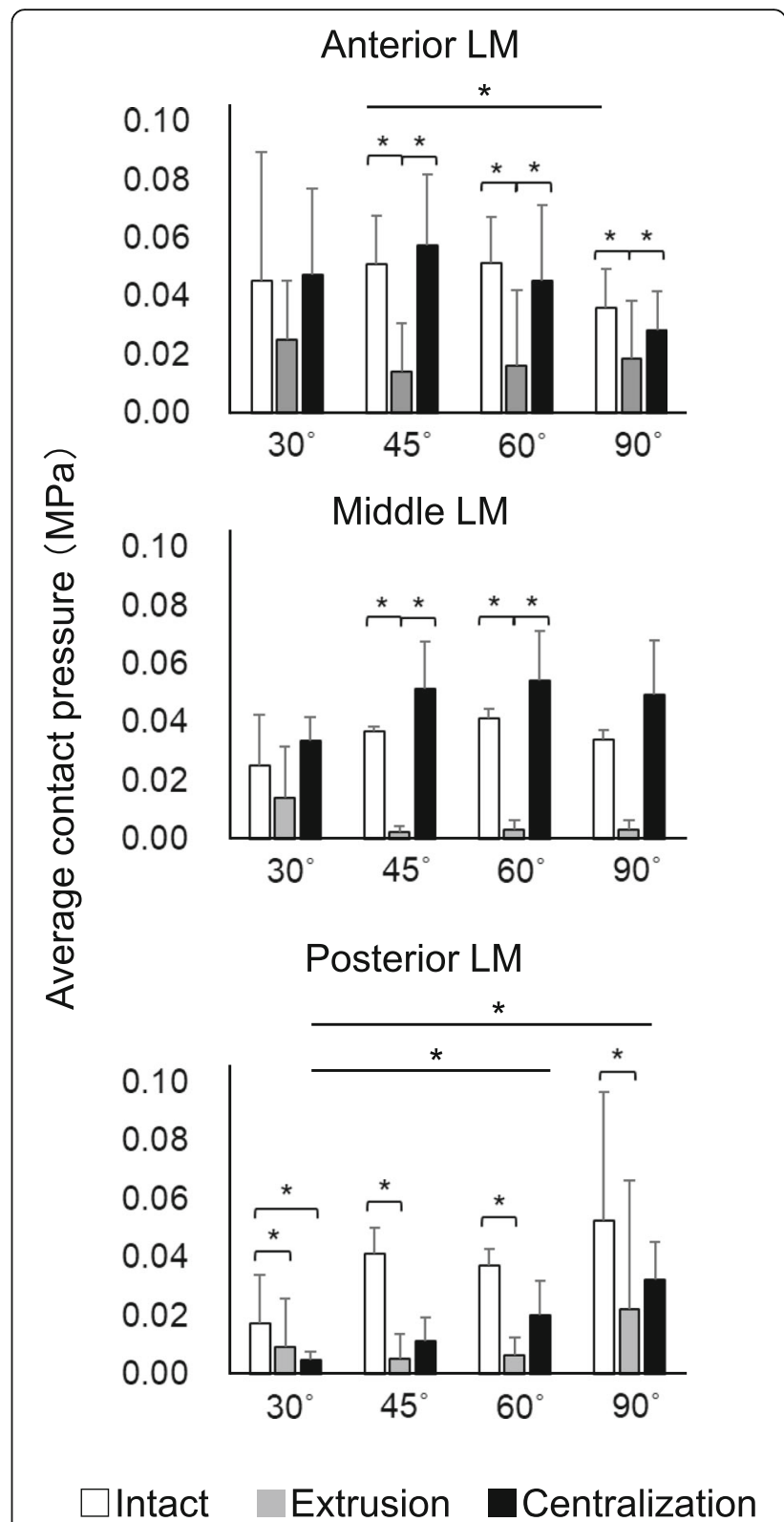

Fig. 4 Quantitative analyses of average contact pressure on the anterior, middle, and posterior LM. The average values with 95\% Cl are shown $(n=8) .\left({ }^{*} P<0.05\right)$

the average contact pressure at $45^{\circ}$ significantly decreased at $90^{\circ}$ in the intact setting; conversely, in the posterior $\mathrm{LM}$, the average contact pressure at $30^{\circ}$ significantly increased at $60^{\circ}$ and $90^{\circ}$ in the centralization setting. In the tibial cartilage, extrusion significantly increased the average contact pressure at $45^{\circ}, 60^{\circ}$, and $90^{\circ}$, whereas centralization significantly decreased it at $90^{\circ}$ (Fig. 5, Supplementary Table 3).

The contact area significantly decreased after extrusion at each flexion angle in the anterior, middle, and posterior LM (Fig. 6, Supplementary Table 4). Contrarily, it 


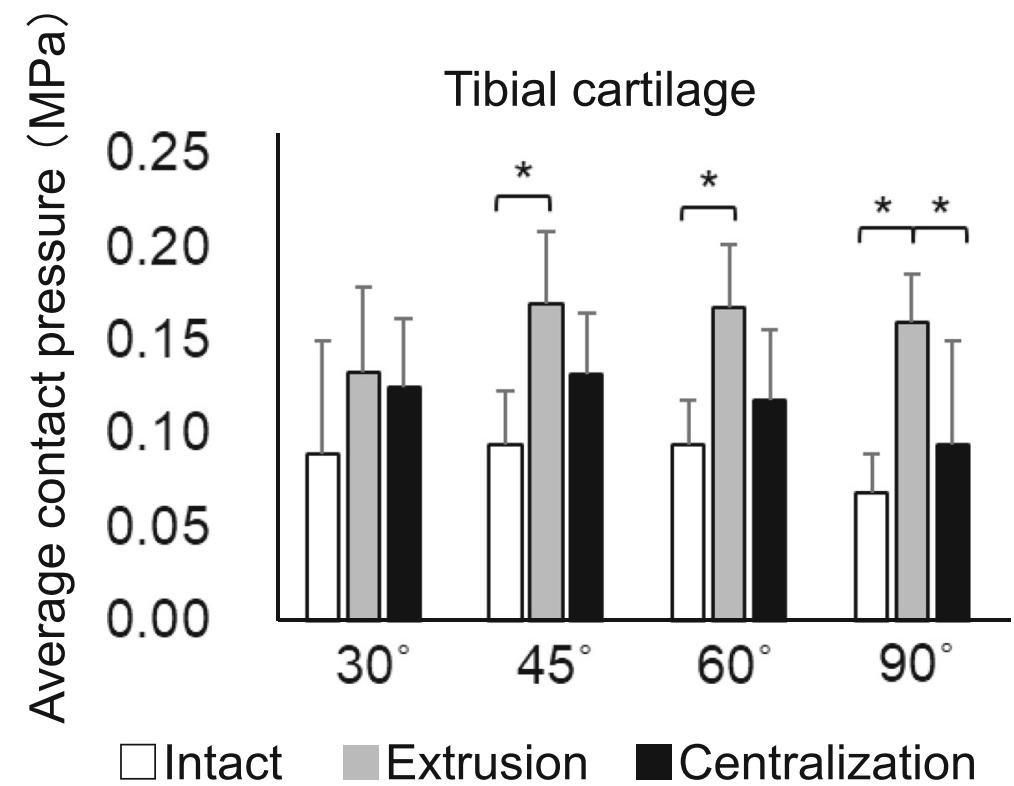

Fig. 5 Quantitative analyses of average contact pressure on the lateral tibial cartilage. The average values with $95 \% \mathrm{Cl}$ are shown $(n=8) .\left({ }^{*} P<0.05\right)$

significantly increased after centralization at each flexion angle in the anterior and middle LM, whereas centralization did not fully recover the contact area in the posterior LM. In all settings, the contact area in the anterior LM appeared to decrease with the knee flexion angle, although there were no significant differences among the areas measured for each angle (Supplementary Table 4). Also, in all settings, the contact area in the posterior LM appeared to increase with knee flexion angle, although there were no significant differences.

\section{Discussion}

In this study, the biomechanics of the extruded and centralized LM were analyzed in porcine knee joints at different flexion angles. In the anterior and middle LM, both the contact pressure and area decreased in extrusion, increasing close to the intact status after the centralization procedure. In this model, the effectiveness of centralization to restore the lost function of the meniscus has been demonstrated in the anterior and middle LM.

We set knee flexion angles at $30^{\circ}, 45^{\circ}, 60^{\circ}$, and $90^{\circ}$. Since the most extended position is approximately at $30^{\circ}$ and the most flexed position is approximately at $90^{\circ}$ in a pig knee joint, we first set the flexion angles every $30^{\circ}$ between $30^{\circ}$ and $90^{\circ}$. We also set $45^{\circ}$ because we set that angle in our previous report [15]. Biomechanical analysis was therefore performed at $30^{\circ}, 45^{\circ}, 60^{\circ}$, and $90^{\circ}$.

We applied $200 \mathrm{~N}$ as an axial compressive force at each setting. The body weight of the pigs which knees we used was approximately $80-100 \mathrm{~kg}$. The pig's center of gravity is near the forelegs and the load on the hind legs is lower than on the forelegs. When standing on a quadruped, the load on single hind leg of an $80-100 \mathrm{~kg}$ pig is approximately $160-200 \mathrm{~N}$ [19]. Two hundred N might be too small as an axial compressive force for biomechanical studies. However, in this study, $200 \mathrm{~N}$ was sufficient to examine the effects of meniscal extrusion and the effects of centralization. In our previous report, $200 \mathrm{~N}$ was the force applied in a similar setting [15]. Furthermore, reported that, in their model, which used similar porcine knees, the in situ force of the LM with a complete radial tear significantly decreased even under an axial load of $150 \mathrm{~N}$ [17]. Therefore, the axial compressive force applied in this study would be large enough to yield clinically significant findings.

Although the deviation distance of the LM, which increased in extrusion, was restored to the intact status in centralization at all angles, the contact pressure and area, decreased in extrusion, were not fully restored in the posterior LM, even after centralization. This was possibly because a $1 \mathrm{~cm}$ width of the posterior root deficiency was left untreated. These results suggest that hoop function should also be reconstructed, if possible, in order to fully restore the load distribution function of the posterior LM. Even so, centralization decreased the contact pressure in the tibial cartilage, and this effect became more obvious as the flexion angle became larger.

The distances between the two markers increased with knee flexion angle in each setting, although no significances were found. This can be explained from the results of the current study; the load distribution moved 


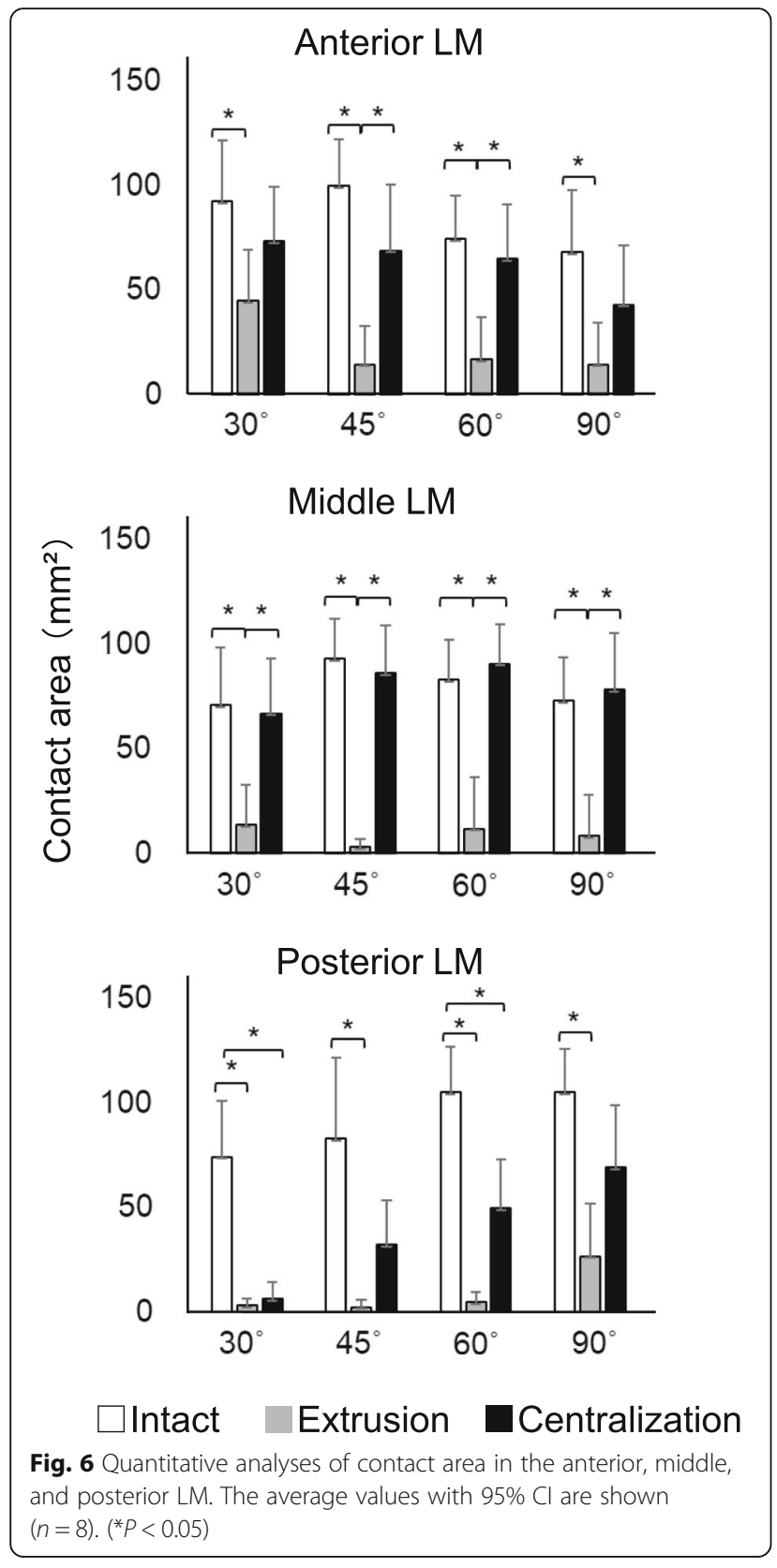

posteriorly as the flexion angle increased. A previous magnetic resonance imaging (MRI) study also supports our results, showing that the lateral femoral condyle and LM consistently displayed a marked posterior translation [20].

To our knowledge, previous reports of biomechanical analysis for the centralization of the extruded meniscus are limited. Nakamura et al. used the centralization procedure in an ACL-reconstructed porcine knee with an irreparable lateral meniscus defect to evaluate the effects of knee biomechanics; they reported that using arthroscopic centralization for the capsular support of the middle segment of the lateral meniscus improved the residual rotational laxity of the ACL-reconstructed knee, which had lateral meniscus dysfunction due to massive meniscal defect [17]. Daney et al., in the only report other than ours [15], measured meniscal extrusion and tibiofemoral contact mechanics at the medial compartment in human cadaveric knees [16]. The anatomic transtibial pull-out root repair and the anatomic transtibial pullout root repair with centralization suture techniques best restored the contact mechanics of the knee and meniscal extrusion when compared with root tear and nonanatomic repair states. However, the degree of extrusion increased as the knee was flexed to $90^{\circ}$. Their study differs from ours in terms of using human knees, examining the inner compartment, and performing the centralization with pullout techniques; both studies, however, showed the effectiveness of centralization.

We previously reported the effect of centralization in a porcine model [15]. The methods used in the two studies were similar in that the experimental settings were the same. The difference between the two studies was that, in the current study, biomechanical analysis was performed at $30^{\circ}, 60^{\circ}$, and $90^{\circ}$ as well as at $45^{\circ}$. Similar results were obtained at $45^{\circ}$ and the new findings were revealed at $30^{\circ}, 60^{\circ}$, and $90^{\circ}$ in knee flexion. Although significant differences of contact area and contact pressure at different angles were not detected, the following trends were observed: Contact area and contact pressure in the anterior and middle LM reached their maxima at $30^{\circ}, 45^{\circ}$, and $60^{\circ}$, while those at the posterior LM reached theirs at $90^{\circ}$.

For limitations, we cut the lateral collateral ligament to insert a sensor from the lateral side; this raised a concern that instability caused by LCL deficiency could have affected the results. We also inserted a pressure mapping sensor between the femoral cartilage and the LM, rather than between the LM and the tibial cartilage, which would have impaired the load-distribution measurements for the entire tibial cartilage. However, the knee joint was stabilized and the loading force applied in the vertical direction; the comparison of evaluated values under intact, extrusion, and centralization settings at each flexion angle will therefore provide important information.

\section{Conclusions}

The centralization procedure could reduce extrusion of the LM and restore the load distribution function of the anterior-middle LM in a porcine model. However, the procedure itself could not restore hoop function in cases with a defect of the posterior LM. 


\section{Supplementary information}

Supplementary information accompanies this paper at https://doi.org/10. 1186/s12891-020-03197-2.

Additional file 1: Supplementary Table S1. Distance between two markers at $200 \mathrm{~N}$ loading. Supplementary Table S2. Average contact pressure for anterior, middle, and posterior LM. Supplementary Table S3. Average contact pressure for the lateral tibial cartilage.

Supplementary Table S4. Contact area for the anterior, middle, and posterior LM.

\section{Abbreviations}

OA: Osteoarthritis; LM: Lateral meniscus; ACL: Anterior cruciate ligament;

LCL: Lateral collateral ligament; PCL: Posterior cruciate ligament;

$\mathrm{Cl}$ : Confidence intervals; MRI: Magnetic resonance imaging

\section{Acknowledgments}

We thank Mr. Scott Adams for English editing.

\section{Authors' contributions}

RK Data collection and draft writing. HKo Conception, manuscript editing, and critical advice. NO Study design, data analysis, and critical advice, and final approval of the article. JM Mechanical setting and interpretation of data. YK Interpretation of data. MM Data collection. HKa Data interpretation. IS Interpretation of data, major manuscript writing, and revised manuscript writing. The author(s) read and approved the final manuscript.

\section{Funding}

This study was supported by JSPS (Grant-in-Aid for Scientific Research) Grant Number 19 K18524 to YK. JSPS funded the purchase of porcine right knee joints in this study. Eight fresh-frozen porcine right knee joints were purchased from Shibaura Zoki Co., Ltd. (Tokyo, Japan). JuggerKnot Soft Anchors ${ }^{\oplus}$ were provided by Zimmer Biomet.

\section{Availability of data and materials}

All data generated or analysed during this study are included in this published article.

\section{Ethics approval and consent to participate}

Not applicable.

\section{Consent for publication}

Not applicable.

\section{Competing interests}

The authors declare that they have no competing interests.

\section{Author details}

${ }^{1}$ Center for Stem Cell and Regenerative Medicine, Tokyo Medical and Dental University, 1-5-45 Yushima, Bunkyo-ku, Tokyo 113-8510, Japan. ²Department of Joint Surgery and Sports Medicine, Graduate School, Tokyo Medical and Dental University, Bunkyo City, Japan.

Received: 19 November 2019 Accepted: 9 March 2020

Published online: 03 April 2020

\section{References}

1. Walker PS, Erkiuan MJ. The role of the menisci in force transmission across the knee. Clin Orthop Relat Res. 1975;109:184-92.

2. Fukubayashi $\mathrm{T}$, Kurosawa $\mathrm{H}$. The contact area and pressure distribution pattern of the knee:a study of Normal and Osteoarthrotic knee joints. Acta Orthop Scand. 2009:51(1-6):871-9.

3. Ambra LF, Mestriner AB, Ackermann J, Phan AT, Farr J, Gomoll AH. Boneplug versus soft tissue fixation of medial meniscal allograft transplants: a biomechanical study. Am J Sports Med. 2019;47(12):2960-5

4. Choi N-H. Radial Displacement of Lateral Meniscus After Partial Meniscectomy. Arthroscopy. 2006;22(5):575.e571-4.

5. Magee T. MR findings of meniscal extrusion correlated with arthroscopy. J Magn Reson Imaging. 2008;28(2):466-70.
6. Puig L, Monllau JC, Corrales M, Pelfort X, Melendo E, Cáceres E. Factors affecting meniscal extrusion: correlation with MRl, clinical, and arthroscopic findings. Knee Surg Sports Traumatol Arthrosc. 2005;14(4):394-8.

7. Stehling C, Luke A, Stahl R, Baum T, Joseph G, Pan J, Link TM. Meniscal T1 rho and T2 measured with 3.0T MRI increases directly after running a marathon. Skelet Radiol. 2010;40(6):725-35.

8. Wenger A, Wirth W, Hudelmaier M, Noebauer-Huhmann I, Trattnig S, Bloecker K, Frobell RB, Kwoh CK, Eckstein F, Englund M. Meniscus body position, size, and shape in persons with and persons without radiographic knee osteoarthritis: quantitative analyses of knee magnetic resonance images from the osteoarthritis initiative. Arthritis Rheum. 2013;65(7):1804-11.

9. Bloecker K, Guermazi A, Wirth W, Benichou O, Kwoh CK, Hunter DJ, Englund $\mathrm{M}$, Resch H, Eckstein F. Tibial coverage, meniscus position, size and damage in knees discordant for joint space narrowing - data from the osteoarthritis initiative. Osteoarthr Cartil. 2013;21(3):419-27.

10. Sharma L, Chmiel JS, Almagor O, Dunlop D, Guermazi A, Bathon JM, Eaton CB, Hochberg MC, Jackson RD, Kwoh CK, et al. Significance of Preradiographic magnetic resonance imaging lesions in persons at increased risk of knee osteoarthritis. Arthritis Rheum. 2014;66(7):1811-9.

11. Willinger $L$, Foehr $P$, Achtnich A, Forkel P, Voss A, Liska F, Lacheta L, Imhoff $A B$, Burgkart R. Effect of lower limb alignment in medial meniscus-deficient knees on Tibiofemoral contact pressure. Orthop J Sports Med. 2019;7(2): 232596711882461

12. Ozeki N, Muneta T, Kawabata K, Koga H, Nakagawa Y, Saito R, Udo M, Yanagisawa K, Ohara T, Mochizuki T, et al. Centralization of extruded medial meniscus delays cartilage degeneration in rats. J Orthop Sci. 2017:22(3):542-8.

13. Koga H, Muneta T, Watanabe T, Mochizuki T, Horie M, Nakamura T, Otabe K, Nakagawa Y, Sekiya I. Two-year outcomes after arthroscopic lateral meniscus centralization. Arthroscopy. 2016;32(10):2000-8.

14. Koga H, Watanabe T, Horie M, Katagiri H, Otabe K, Ohara T, Katakura M, Sekiya I, Muneta T. Augmentation of the pullout repair of a medial meniscus posterior root tear by arthroscopic centralization. Arthrosc Tech. 2017:6(4):e1335-9.

15. Ozeki N, Koga H, Matsuda J, Kohno Y, Mizuno M, Katano H, Tsuji K, Saito T, Muneta T, Sekiya I. Biomechanical analysis of the centralization procedure for extruded lateral menisci with posterior root deficiency in a porcine model. J Orthop Sci. 2019.

16. Daney BT, Aman ZS, Krob JJ, Storaci HW, Brady AW, Nakama G, Dornan GJ, Provencher MT, LaPrade RF. Utilization of Transtibial centralization suture best minimizes extrusion and restores Tibiofemoral contact mechanics for anatomic medial meniscal root repairs in a cadaveric model. Am J Sports Med. 2019:47(7):1591-600.

17. Nakamura T, Linde MA, Marshall BD, Koga H, Muneta T, Smolinski P, Fu FH. Arthroscopic centralization restores residual knee laxity in ACL-reconstructed knee with a lateral meniscus defect. Knee Surg Sports Traumatol Arthrosc. 2019:27(11):3699-704

18. Tachibana Y, Mae T, Fujie H, Shino K, Ohori T, Yoshikawa H, Nakata K. Effect of radial meniscal tear on in situ forces of meniscus and tibiofemoral relationship. Knee Surg Sports Traumatol Arthrosc. 2016;25(2):355-61.

19. Conte S, Bergeron R, Gonyou H, Brown J, Rioja-Lang FC, Connor L, Devillers $\mathrm{N}$. Measure and characterization of lameness in gestating sows using force plate, kinematic, and accelerometer methods1. J Anim Sci. 2014;92(12): 5693-703.

20. Thompson WO, Thaete FL, Fu FH, Dye SF. Tibial meniscal dynamics using three-dimensional reconstruction of magnetic resonance images. Am J Sports Med. 2016;19(3):210-6.

\section{Publisher's Note}

Springer Nature remains neutral with regard to jurisdictional claims in published maps and institutional affiliations. 